\title{
Psychiatrists and the learning disabilities health service
}

\author{
Sally-Ann Cooper and Nicola M. Bailey
}

\begin{abstract}
A study of all trusts in England and Wales providing specialist health services for people with learning disabilities attracted an $83.9 \%$ response rate. Considerable variation exists with regard to the quantity of services. The relationship between the learning disabilities psychiatrist and National Health Service leaming disabilities bed-numbers and leaming disabilities health professionals from other disciplines is explored. An appropriate balance needs to be kept in these ratios to reduce stress and bumout.
\end{abstract}

The role of the learning disabilities psychiatrist has changed considerably in recent years (Reid, 1994). In the days of the large institutions, the psychiatrist fulfilled the role of superintendent, responsible for all aspects of the life of the person with learning disabilities. Now, with the advent of care in the community and clearly defined routes of recognised training, the psychiatrist's clinical role is more focused. Many psychiatrists contribute towards multi-agency planning of care for people with learning disabilities and so are still able to influence and improve the broader aspects of people's lives. Clinical duties, however, are more likely to be focused on working with multi-disciplinary colleagues using physical, psychological, social and developmental methods of treatment to help people with mental illness, challenging behaviour, epilepsy, autism. developmentally-related problems and personality difficulties and family problems.

Learning disabilities psychiatrists work across a range of services, which may include acute assessment and treatment in-patient units, longstay National Health Service (NHS) units (sometimes small bungalows in the community, sometimes complexes of several small units in close proximity, in some cases still the institutions), NHS respite care units and day hospitals. Much work is domiciliary, and patients are additionally seen in out-patient clinics. The learning disabilities psychiatrist is also likely to work in the social services day centres, respite care units and residential homes, and in private care homes and day services. Charitable organisations, such as Mencap, provide residential homes and may provide day care, with the learning disabilities psychiatrist working in these settings. This involves considerable time driving, and in liaising with carers from a range of agencies (people with learning disabilities cannot usually give full histories themselves, and current carers may have only known the person for a short time).

This changing style of working, together with developments in the understanding of clinical presentations of mental illness in people with learning disabilities, and greater public expectations that treatable illnesses are treated rather than just tolerated, have led to increased demands on the learning disabilities psychiatrist's time.

Several researchers have debated and described the range of the specialist services required to meet the health needs of people with learning disabilities (Bouras \& Drummond, 1989; Day, 1993; Mansell, 1993; Reid, 1994; Bouras et al, 1995; Department of Health, 1995. Gravestock \& Bouras, 1995). However, there has been little work on the relationship of the learning disabilities psychiatrist to these services. Piachaud (1989) undertook a detailed breakdown of the learning disabilities psychiatrist's workload. He gathered estimates from 13 consultants of the time required for items of medical activity, including patient contacts, indirect clinical time, and time spent on nonclinical activity (e.g. management and teaching). He calculated that a catchment population of 200000 required 90 hours of medical time, which should be split between two consultants supported by senior clinical medical officers/ clinical assistants or by trainees. He describes how the amount of time required to be spent on indirect clinical activity (arising from discussion with others) increases, the smaller the hospital component of the postholder's job, due to a greater need for liaison in community settings. The Royal College of Psychiatrists now recommends one consultant in learning disabilities psychiatry per 100000 catchment population (Royal College of Psychiatrists, 1992).

Psychiatrists work with nurses and other therapists to meet the health needs of their patient group. Some services are better staffed than others, and have more physical facilities than others. The extent of these differences throughout England and Wales has recently 
been reported (Bailey \& Cooper, 1997). It is also of interest to examine the way that the learning disabilities psychiatrist relates to the learning disabilities services and other professionals working in that service.

\section{The study}

An 11-item questionnaire was sent to all NHS trusts in England and Wales who provide specialist health services to people with learning disabilities (Bailey \& Cooper, 1997). The chief executive of each trust was asked to pass it to the relevant manager for completion: a copy was also sent to the learning disabilities lead clinician/ clinical director for information. A repeat questionnaire was sent to non-respondents after one month.

\section{Findings}

Completed questionnaires were returned by 135 out of 161 trusts (83.9\%). Median and centile scores have been quoted in the tables (as well as mean scores) as results tended to be skewed to the right rather than being normally distributed.

The catchment population size per learning disabilities consultant ranged between 12963 and 2800000 (pro rata). This discrepancy is accounted for in part by a variable consultant: non-consultant learning disabilities psychiatrist ratio but also by under-resourcing by some trusts. The median catchment population per consultant was 260000 . This equated with the number of learning disabilities psychiatrists per 100000 population having a median score of 0.76 and mean score of 1.1. Exploration of the numbers of training grade staff and non-consultant career grade staff per consultant showed a variable distribution across England and Wales (Table 1). For each trust, the combined number of supporting medical staff per consultant learning disabilities psychiatrist has a distribution with mean of 1.24 and median of 1.00 . Clearly, for the same catchment population size, the clinical workload of a consultant with 4.3 supporting medical staff is likely to be less than that of a consultant with none, particularly when these staff are non-consultant career grade staff. This wide variation across the country makes it difficult to draw comparisons between trusts regarding the workload per consultant. For this reason the following results refer to all grade of learning disabilities psychiatrists.

Table 2 demonstrates the number of NHS beds per learning disabilities psychiatrist. This refers to beds for the sole use by people with learning disabilities (e.g. with additional mental illness
Table 1. Number of supporting medical staff per consultant learning disabilities psychiatrist

\begin{tabular}{|c|c|c|c|c|}
\hline & Median & $\begin{array}{l}\text { 5th } \\
\text { centile }\end{array}$ & $\begin{array}{l}\text { 95th } \\
\text { centile }\end{array}$ & Mean \\
\hline Training grades & 0.00 & 0.00 & 2.00 & 0.54 \\
\hline $\begin{array}{l}\text { Non-consultant } \\
\text { career grades }\end{array}$ & 0.40 & 0.00 & 2.70 & 0.67 \\
\hline $\begin{array}{l}\text { Combined training } \\
\text { and non- } \\
\text { consultant career } \\
\text { grades }\end{array}$ & 1.00 & 0.00 & 4.30 & 1.24 \\
\hline
\end{tabular}

and challenging behaviour). It includes local bed provision for people with learning disabilities who need forensic psychiatric services; however, the special hospitals were excluded. There is considerable variation with regard to the number of long-stay beds and day places that the learning disabilities psychiatrist has responsibilities towards. Regarding long-stay beds, 30 trusts $(23.6 \%)$ had none while five trusts had more than 100 NHS long-stay beds per learning disabilities psychiatrist. In the majority of trusts (70.4\%) learning disabilities psychiatrists had responsibilities for acute assessment and treatment beds, with a mean of 3.0 and median of 1.8 beds per learning disabilities psychiatrist. Considering responsibilities per learning disabilities psychiatrist for a total bed number of each trust revealed a mean of 34.1 and median of 21.9 beds. If NHS day places are included with inpatient beds, the total 'bed/place' number per learning disabilities psychiatrist has a mean of 46.9 and median of 28.0 .

Table 2. Number of NHS beds per learning disabilities psychiatrist for 135 trusts

\begin{tabular}{|c|c|c|c|c|}
\hline & Median & $\begin{array}{l}\text { 5th } \\
\text { centile }\end{array}$ & $\begin{array}{l}\text { 95th } \\
\text { centile }\end{array}$ & Mean \\
\hline $\begin{array}{l}\text { Learning disabilities } \\
\text { assessment/ } \\
\text { treatment beds }\end{array}$ & 1.8 & 0.0 & 12.0 & 3.0 \\
\hline $\begin{array}{l}\text { Learning disabilities } \\
\text { respite-care beds }\end{array}$ & 1.2 & 0.0 & 12.3 & 2.8 \\
\hline $\begin{array}{l}\text { Learning disabilities } \\
\text { long-stay beds }\end{array}$ & 15.0 & 0.0 & 77.0 & 27.4 \\
\hline $\begin{array}{l}\text { NHS beds of all } \\
\text { learning disability } \\
\text { types }\end{array}$ & 21.9 & 0.0 & 87.4 & 34.1 \\
\hline $\begin{array}{l}\text { Learning disabilities } \\
\text { day places }\end{array}$ & 0.0 & 0.0 & 58.0 & 12.0 \\
\hline $\begin{array}{l}\text { NHS beds of all } \\
\text { leaming disabilities } \\
\text { types, including } \\
\text { day places }\end{array}$ & 28.0 & 0.0 & 200.4 & 46.9 \\
\hline
\end{tabular}


Table 3 describes the relationship between learning disabilities health professionals per learning disabilities psychiatrist for the 135 trusts. It can be seen from the median scores that the average learning disabilities psychiatrist relates to and works with 3.1 community nurses, 1.0 psychologist, 0.8 occupational therapists, 0.7 physiotherapists and 0.7 speech therapists.

\section{Comment}

There was a high response rate to this questionnaire which probably relates to a current high level of interest into the various specialist health service provisions for people with learning disabilities. It is not possible to determine whether the $16.1 \%$ of non-respondents are atypical.

For trusts at the 50th centile each consultant is supported by 1.0 junior/non-consultant career grade learning disabilities psychiatrist. Learning disabilities psychiatrists working for trusts at the 50th centile each have responsibilities for a total of 21.9 NHS learning disabilities beds ( 1.8 acute assessment and treatment beds, 1.2 respite-care beds and 15.0 long-stay beds). They relate to a number of other learning disabilities health care professionals.

It is important that services develop in a comprehensive way so that as far as possible. health needs can be met by local services. Learning disabilities psychiatrists work across the full range of specialist services and so are in a position to recognise deficits and excellence in their service. The quantity of specialist learning disabilities services varies across the country with some trusts providing comprehensive services and others having a shortage of resources (Bailey \& Cooper, 1997). Few learning disabilities psychiatrists would welcome having to deliver a service to a population of 2800000 (pro rata),

Table 3. Number of other learning disabilities health care professionals per learning disabilities psychiatrist for 135 trusts

\begin{tabular}{lllll}
\hline & \multicolumn{3}{c}{$\begin{array}{c}\text { 5th } \\
\text { Median centile }\end{array}$} & $\begin{array}{c}\text { 95th } \\
\text { centile }\end{array}$ \\
Mean
\end{tabular}

the upper end of the range in this survey, as this task is surely impossible. The number of consultant learning disabilities psychiatrists in many trusts does not reach the recommended level (Piachaud, 1989; Royal College of Psychiatrists, 1992). Non-consultant career grade learning disabilities psychiatrists clearly have a role to play in the provision of services. However, these appointments should not be used as an alternative to consultant posts.

The number of beds required by a trust will depend upon the size of the population and other local factors. However, 'beds' have to be 'serviced' and this draws upon the time of the learning disabilities psychiatrist. Increasing bed numbers to meet local requirements without increasing psychiatric staffing contributes to an unacceptable workload and hence stress. The learning disabilities psychiatrists found in this study to be responsible for over 200 NHS beds, in addition to a community and out-patient workload, are facing an unenviable task. Similarly, learning disabilities psychiatrists whose time is being sought by over 17 community nurses, or over seven psychologists, are likely to be unreasonably stretched. Preferential development of one part of the service at the expense of another, e.g. community nursing as opposed to psychiatry, or vice versa, has a knock-on effect in generating work for the other professional (as a larger proportion of the population's hidden morbidity is revealed), and can lead to stress and burnout. An appropriate blance needs to be kept in the ratio between learning disabilities psychiatrists and bed and staff numbers. Future service developments can then concentrate on greater quantity and better quality rather than different ratios of professionals.

\section{Acknowledgements}

We acknowledge the support provided by Miss Denise Hamson and Mrs Jean Davis, and the contribution made by the participating trusts.

\section{References}

BAILEY, N. M. \& COOPER, S.-A. (1997) The provision of specialist health services to people with learning disabilities in England and Wales. Journal of Intellectual Disability Research, 41, 52-59.

BOURAS. N. \& DRUMmOND. C. (1989) Community psychiatric service in mental handicap. Health Trends, 21, 72.

Bouras, N., Holt, G. \& Gravestock, S. (1995) Community care for people with learning disabilities: deficits and future plans. Psychiatric Bulletin. 19. 134-137.

DAY, K. A. (1993) Mental health services for people with mental retardation: a framework for the future. Journal of Intellectual Disabilities Research. 37(suppl. 1), 7-16. 


\section{ORIGINAL PAPERS}

DePaRTMENT OF HEALTH (1995) The Health of the Nation: $A$ Strategy for People with Leaming Disabilities. London: HMSO.

GRAVESTOCK, S. \& BOURAS, N. (1995) Services for adults with learning disabilities and mental health needs. Psychiatric Bulletin. 19, 288-290.

MANSELL, J. L. (1993) Services for People with Learning Disabilities and Challenging Behaviour or Mental Health Needs. London: HMSO.

PIACHAUD, J. (1989) Calculating the medical time required in the psychiatry of mental handicap. Psychiatric Bullein. 13, 486-489.

ReID. A. H. (1994) Psychiatry and learning disability. British Journal of Psychiatry. 164, 613-618.
ROYAL COLLEGE OF PSYCHIATRISTS (1992) Mental Health of the Nation: The Contribution of Psychiatry. London: Royal College of Psychiatrists.

*Dr Sally-Ann Cooper, Consultant in Learning Disabilities Psychiatry. Rockingham Forest NHS Trust, St Mary's Hospital, London Road, Kettering, Northants NN15 7PW; and Nicola M. Bailey, Specialist Registrar, Oxford Higher Training Scheme in Learning Disabilities Psychiatry

*Correspondence 